\title{
واقع تطبيق ادارة المعرفة فى جهاز الارشاد بمحافظة المنوفية
}

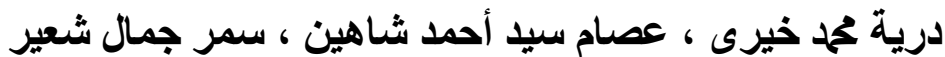 \\ قسم الارشاد الزراعى والمجتمع الريفى ـ كلية الزراعةـ جامعة المنوفية ـ شبين الكوم ـ مصر فير
}

Received: Dec. 12, 2018

Accepted: Dec. 29, 2018

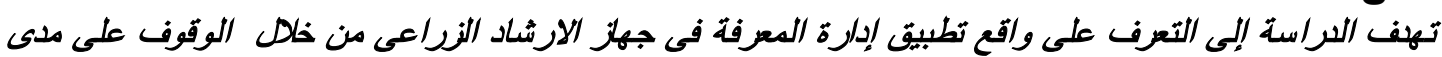

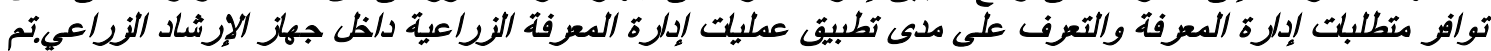

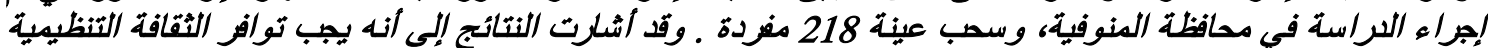

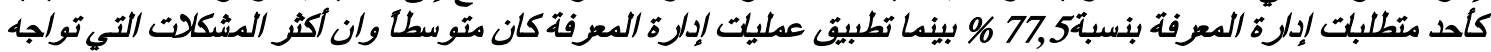

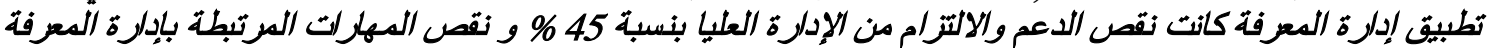

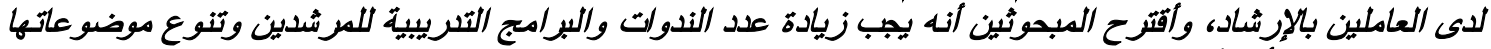

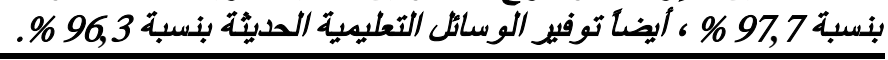

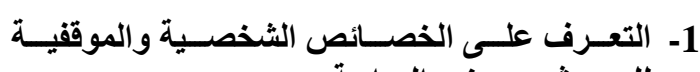

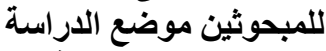

2- الوقوف على مدى توافر متطلبات إدارة نظام المعرفة

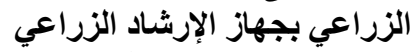

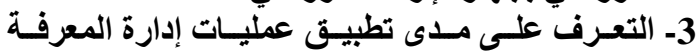

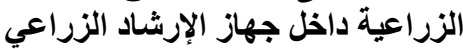

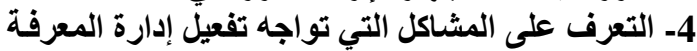

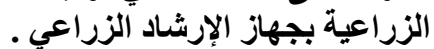

5- إبراز أهم المقترحسات لتطوير دور الإرشـاد في إدارة المعرفة الزراعية.

\section{الاطار النظرى}

المعرفة: يعرفها حسن ( 1998) على أنها عبارة عن

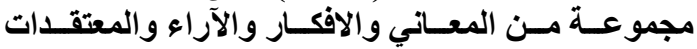



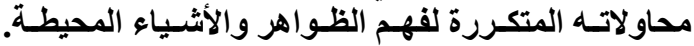
يرتبط مفهوم المعرفة بمفهومين سابقين له وهئ وهما البيانات

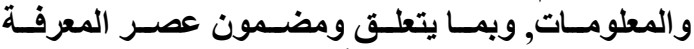

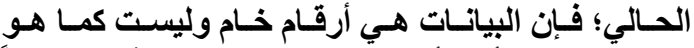

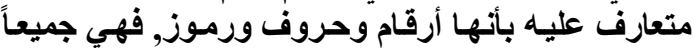

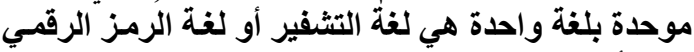

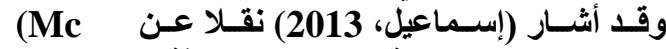
: إلى ستة خصائص للمعرفة وهي لفي Dermott)

$-2$

$-4$

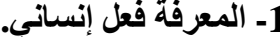
المعرفة تنتج عن التفكير. 3- المعرفة تنتولد في اللحظة الراهنة.

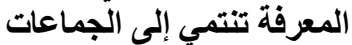
5- المعرفة تتو الدها الجماعات بطريقة مختلفة. 6- - المعرفة تتولد تر اكمياً

مصادر المعرفة عرف عبيا (2016) مصدر المعرفة بأنه تلك المصادر الأي يحوي أو يجمع المعرفة. من أهم مصادر المعرفة و التي تقسم إلى قسمين وهم:
المقدمة والمشكلة البحثية تعد المعرفة المصدر الرئيسي والإستر التيجي الأكثر

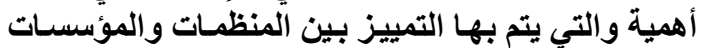

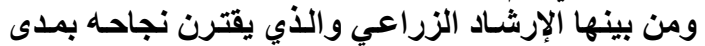

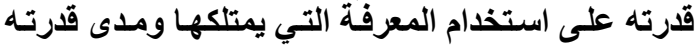

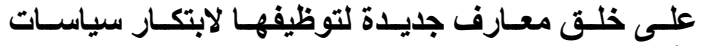
وأسـاليب عمل جديدة تلبي احتياجـات المزارعين والذئي ينعكس على مستويات الاداء.

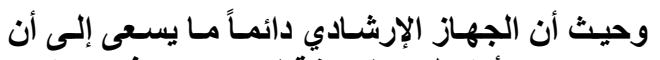

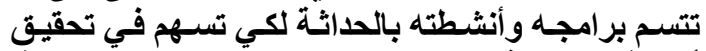

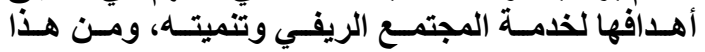

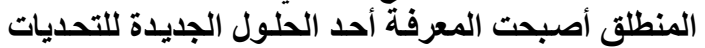

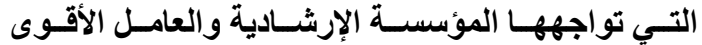

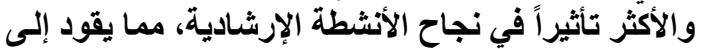

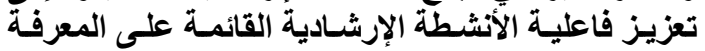

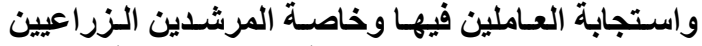

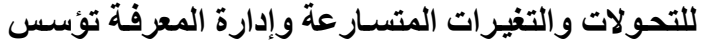

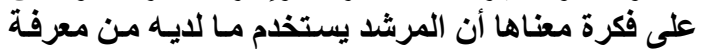

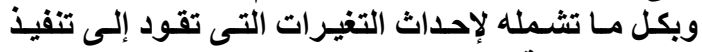

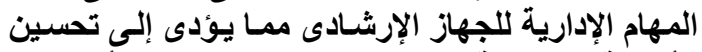

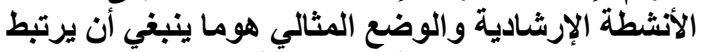

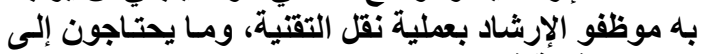

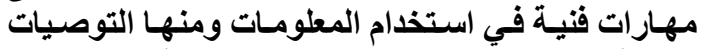

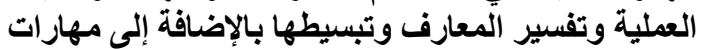

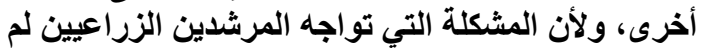

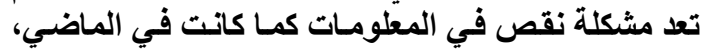

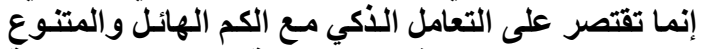

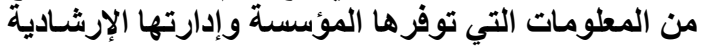

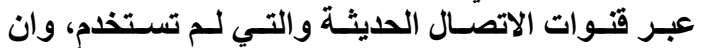

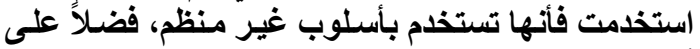


وتطبيقها، لأنهم لا يعرفون الوسائل الملائمة لها.

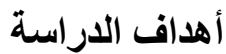


الدراسات التطبيقية و التطويرية وغيرها القابل للاستخدام

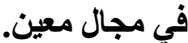
أهمية إدارة المعرفة:

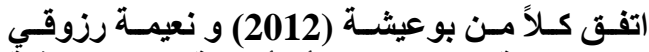

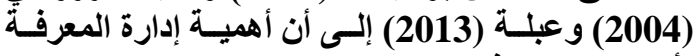
تأتى من دور ها فيما يلي: الئي 1- تبسيط العمليات وخفض التهائ التكاليف عن طريق التخلص

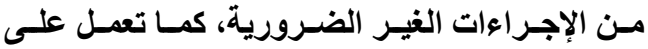

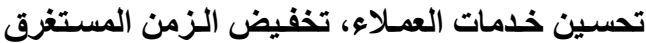
في تقديم الذامات المطلوبة.

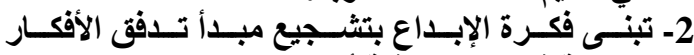

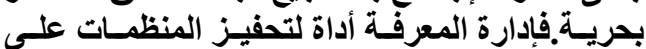

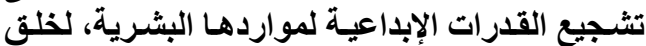
معرفة جيدة 3- تنسـيق أنثطة المنظمـة المختلفـة في اتجـاه تحقيق أهدافها.

4- تعزيز قدرة المنظمة للاحتفـاظ بـالأداء المنظم المعتمد على الخبرة والمعرفة وتحسينه.

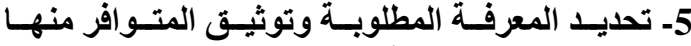

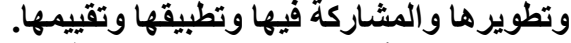

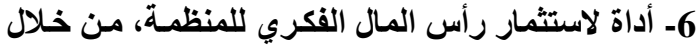

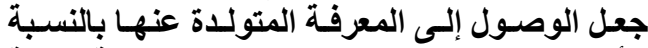
للأثـخاص الآخرين المحتـاجين إليهـا عمليـة سـهـية

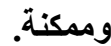

7- تحفيز المنظمات على تجديد ذاتها ومواجهة التغييرات البيئية غير المستقرة.

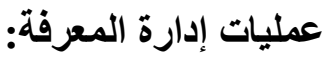
أوضح kucza (2001) إلى أن المهمة العامة لإدارة المعرفة هي إدارة عملية خلق،خزن،المشاركة بالمعرفة بالإضافة إلى المهام الأخرى ذات العلاقة بهذه العمليات وفيما يلي توضيح لأهم عمليات إدارة المعرفة كما أوردها

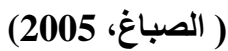
1- اكتساب المعرفة: ويقصد بها قيـام المنظمـة بالبحث عـن الخبـرات التـي تريــها سـواء كانـت داخليـاً أو

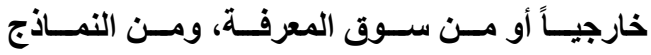
المسـتخدمة في عمليـة اكتســاب المعرفــة جديـدة، ويتشارك هؤلاء الناس مع الآخرين في المعرفة التي اكتسبوها وتبدأ العملية من جديد في دورة مستمرة. 2- تخزين المعرفة: بعد اكتساب المعرفة، يتم تخزينها

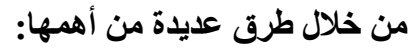

1- المصادر الخارجية: ومنها المصادر المكتبات

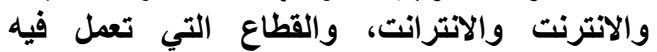

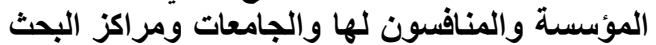

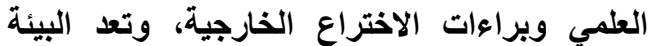

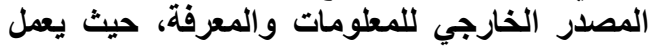
الأفراد على مختلف مستوياتهم التنظيمية من خلال الترلية أحد أو كل المدركات الحسية (السمعية، البصرية،

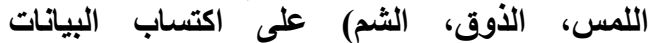
والحوادث من البيئة ومن خلأل قدراتهم الإدراكية والفهمية مثل (التأمل والفهم والتسبيب والتهن والحكم)

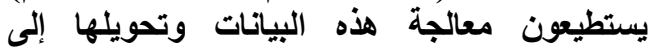
معلومات، ومن خلال الخبرة والأكاء و التفكير والتعلم ولئل

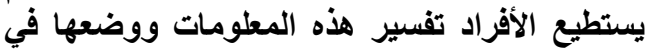
معنى.

2- المصادر الداخلية : تتمثل المصادر الداخلية في

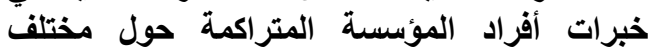
الموضوعات وقدرتها على الاستفادة من تعلم الأفراد

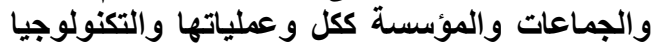

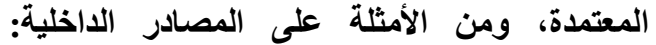

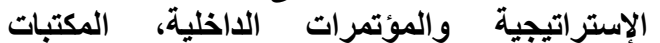

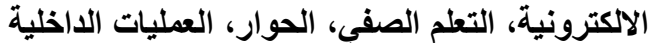

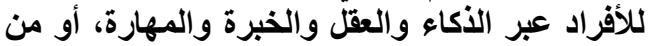
خلال التعلم بالعمل أو البحوث وبراءل واءرة والت الاختراع أون

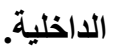

أشـار إسماعيل (2013) إلى أن كثيراً من البـاحثين

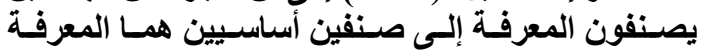
الضمنية الكامنة، والمعرفة الظاهرة الواضحة، وفينة وفيما يلي لئي عرض لهذا التصنيف:

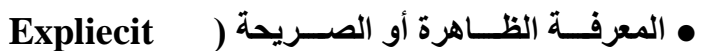

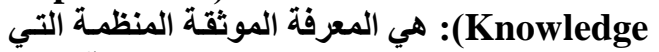

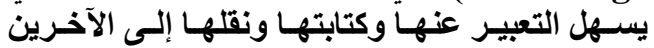

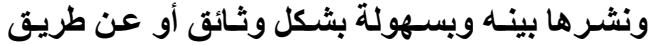
وسائل التعليم والاتصالات المختلفة.

• المعرفة الضمنية (Tacit Knowledge): هي المئية

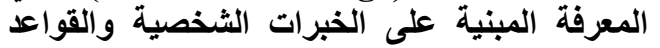

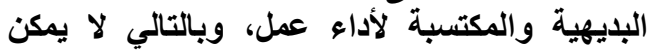
التعبير عنها بسهولة ويصعب نقلها إلى الآخرين.

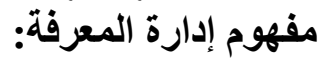

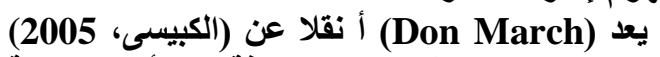
اول من استخدم مصطلح إدارة المعرفة على أنها المرحلة

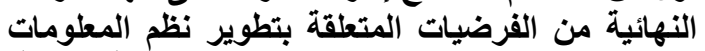
لكنه لم يشر إليها بشكل مستقل أو بوصفها عملاً مستقلّاً. ويثير (مراياتي، 2000) إلى أن إدارة المئئ المعرفة هي الاستغلال الأمثل للمعلومات والبياتيات أليات من خلال توظيف

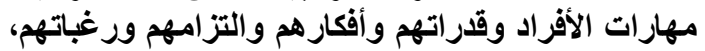

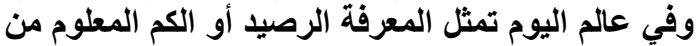
المعرفة الناتج من البحث العلمي أو التفكير المنطقي أو الون 
و التحكم بها وإدارتها وتخزينها وتعزيزها ومضـاعفتها وإعادة استخدامها.

• العامل الثقافى: يتطلب تطبيق إدارة المعرفة خلق ثقافة إدافة

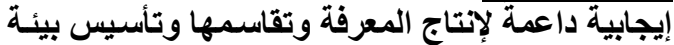

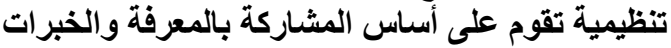

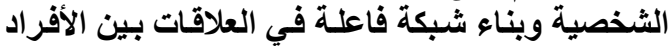
وتأسيس ثقافة تنظيمية داعمة للمعرفة فيكة



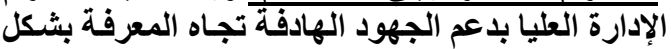

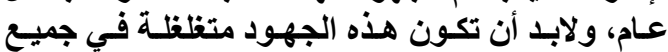

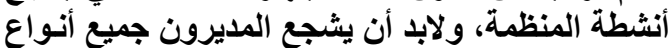

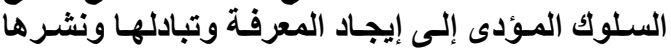

ونقلها.

$$
\text { الطريقة البحثية }
$$

تعد تلك الاراسة من النوع الوصة الوصفى تم إجر اءع الدراسة

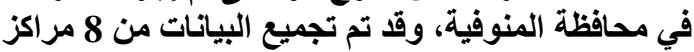

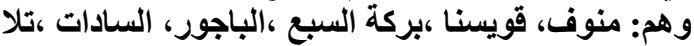

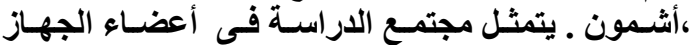

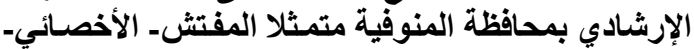
المرشد-الأخصائيات الريفيات، وتم سحب عينة الرئة عشو الئية

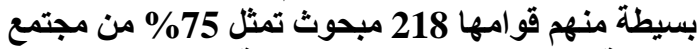
الدراسة، وتم تجميع البيانات الميدانية باستخدام استمارة استبيان خلال شهر يوليو 2018.

$$
\text { المتغيرات البحثية وكيفية قياسها }
$$

1- الوظيفة : ويقصد بـه التعرف على وظيفة المبحوث الحالية وتم قياسها من خلال مقياس اسمى وإعطاء 1

للمفــش و2 للأخصــائي و3 درجــات للمرشـــ، 4

للرائـدات الريفيـات وتـم حصـرها عـدياً وبالنسـبة

$$
\text { المئوية. }
$$

2- المؤهل : ويقصد بـه التعرف على المؤهل الدراسي

الـذي حصـل عليـة المبحـوث وتـم قياسـه مـن خـلال

إعطـاء 1 للمؤهل المتوسط و2 للمؤهل العـالي و 3

للار اسات العليا وتم حصرهم عددياً وبالنسبة المئوية.

3- التخصـص : ويقصــ بـه التعرف على التخصـص

الدقيق للمبحوث وأعطى إرشـاد زراعي 3 ، وشعبة

عامـة 2 وتخصصــات أخـرى 1 وتـم حصـرها عددياً

$$
\text { وبالنسبة المئوية. }
$$

قيام كل فرد في المنظمة بتسجيل كل ما يحدث له وأية معلومات جديدة في مكان معين، سواء في ملفـات عادية أو في شبكة الحاسب الآلي، بحيث تكون متاحة لكل أفراد

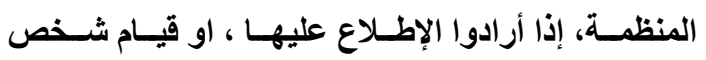
مسئول بجمع المعلومات وتخزينها بدقة وبطريقة يسهل المهل اسـتخدامها مـن الجميـع، دون الاهتمــام بتحليـل وتنقيـة المعرفة أو بنشرها وتداولها بطرقة فعالة.

3- نقل المعرفة: يعتبر نقل المعرفة الحلقة الثالثة في

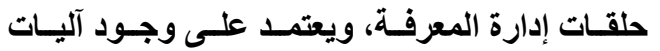

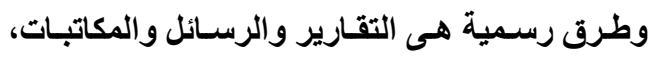

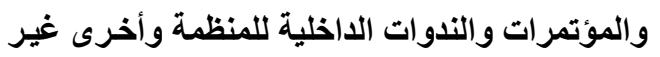

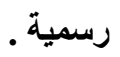
4- تطبيق المعرفة: ويتطلب هذا التطبيق تنظيم المعرفة،

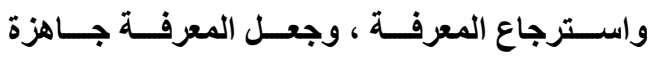

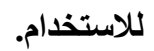

متطلبات تطبيق إدارة المعرفة.

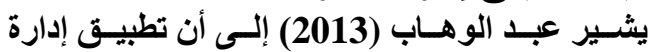

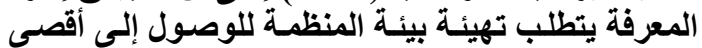

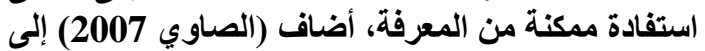

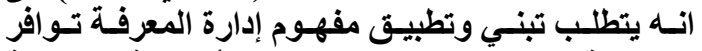
مجموعة من المقوميات والمتطلبـات الأساسية بالمنظمـة

$$
\text { فيما يلي: }
$$

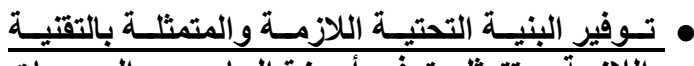

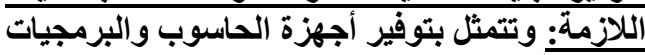

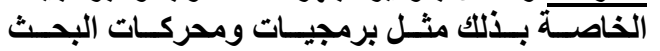

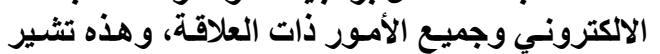
بطريقة أو بأخرى إلى تقنية وأنظمة المعلومات.

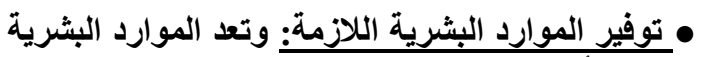

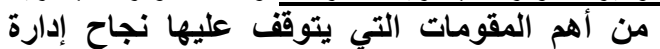
المعرفة في تحقيق أهدافهها، وهم ما يعرفون بأفئر أفراد المعرفة التي تقع على على عاتقهم مسئولية القيام بالنشاطات اللازمة لتوليد المعائ المعرفة وحفظها وتوزيعها، بالإضافة إلى القيام إعداد البرمجيات اللازمة.

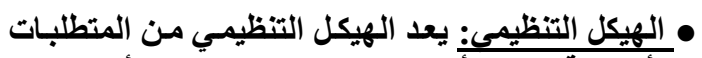

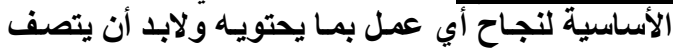

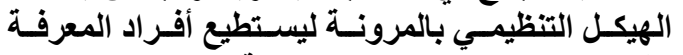

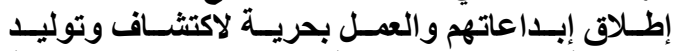

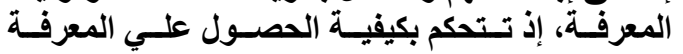


ويقصد بـه التعرف على أهم المشكلات التي تواجـه تطبيق إدارة المعرفة وتم حصر عدد من المشكلات وتم قياسه من خلال مقياس رتبي من 3 درجات وطلب من المبحوث تحديد رأيه وأعطى موافق 3 والى حد مـا 2 و

غير موافق 1 وتم حصرهم عددياً وبالنسبة المئوية.

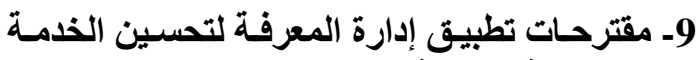
الإرشادية المقدمة للمزار الطين

ويقصد به التعرف على مقترحسات المبحوثين لتئن لتطبيق

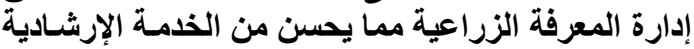

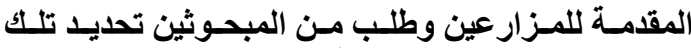
المقترحات وتم حصرها لعدين علدياً وبالنسبة المئوية. نتائج الدراسة أولاً: البيانات الثخصية والموقفية للمبحوثين أوضحت النتائج في الجدول رقم (1) أن 41,3\% من

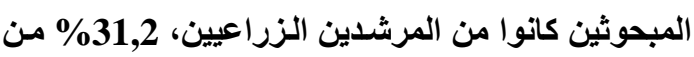

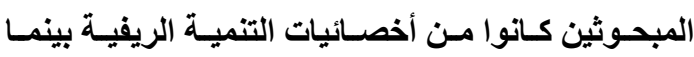
23,8 من المبحوثين كانوا من الأخصائيين الزراعيين

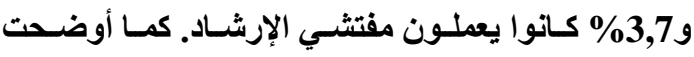
النتائج أن 53,2\% من المبحوثين حاصلين على دبلوم مقابل 41,3 \% أصلين على بكالوريوس العلوم الزراعية و5,5\% حاصلين على دراسـات عليا في مجال الزراعة

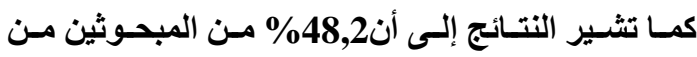
تخصصات أخرى غير الإرشاد، وان 28,4\% منهم شعبة عامة مقابل 23,4 \% تخصص إرشاد زراعي. وقد أشسـارت البيانـات إلـى أن 61\% مـن المبحـوثين يقعون في الفئة العمريـة من48 سنة إلى 59 سنة وان \%29,4 من المبحوثين من الفئة العمريـة من 37 سنـة إلى اقل من 48 سنة وأن 9,6\% من المبحوثين في الفئة

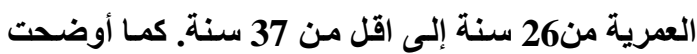
البيانات أن 52,8\% كاتت خبرتهم من سنة إلى اقل من 12 سنة، وأن 39,4\% كانت خبراتهم من 12 سنة إلى أقلّ من 23 سنه، و7,8\% خبراتهم تتراوح من 23 إلى
4- السن : يقصد به التعرف عمر المبحوث وتم حصرهم عددياً وبالنسبة المئوية. 5- عدد سنوات الخبرة بالإرشساد : يقصد بـه التعرف على عدد سنوات العمل في الإرشـاد الزراعي وتم

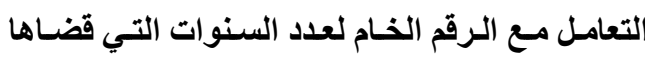

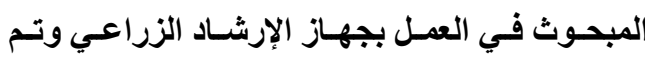
حصرها عدديا وبالنسبة المئوية. 6ـ التعرف على مدى توافر متطلبات إدارة المعرفـة:

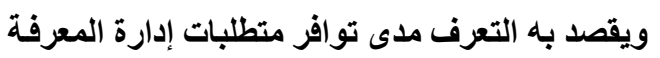

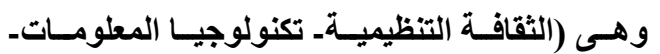
العنصر البشرى - إستراتيجية إدارة المعرفة ـ توافر

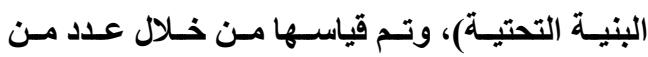

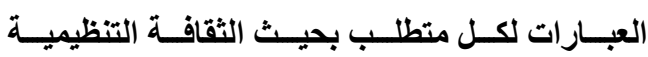
(5 عبـارات)، تكنولوجيـا المطومسـات (3 عبـارات)، العنصـر البثـرى (5 عبـارات)، إسـتراتيجية إدارة

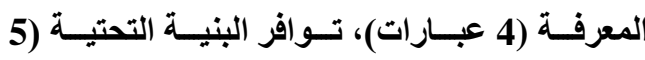
عبارات)، وطلب من المبحوث تحديد درجة التوافر

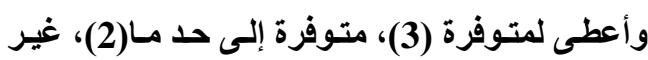
متوفرة(1) وتم حصر ها عددياً وبالنسبة المئوية. 7- التعرف على مدى تطبيق مراحل إدارة المعرفة ويقصد بـه التعرف على مدى تطبيق مراحل إدارة

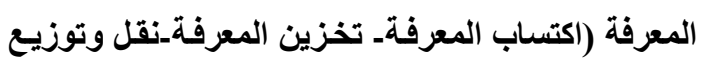
المعرفة ـ تطبيق المعرفة ) وتم قياسها من خلال عدد من

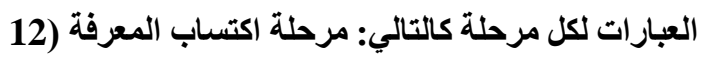
عبارة)، مرحلة تخزين المعرفة (9 عبارات)، مرحلة نقل

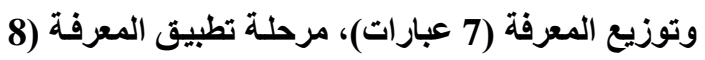

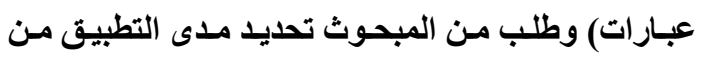
خلال مقياس من 4 درجات أعطى فيها يطبق 4 أحيانـا 3 ونسادراً 2 ولا يطبـق1 وتـم حصـرهم عـدديا وبالنسـبة

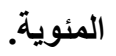

8ـ المشكلات التـي تواجـه إدارة المعرفـة في جهـاز الإرشاد 


\begin{tabular}{|c|c|c|c|c|c|}
\hline \multicolumn{6}{|c|}{ خصائص الشخصيه والموفيه للمبحوتين. } \\
\hline \multicolumn{3}{|c|}{ السن } & \multicolumn{3}{|c|}{ الوظيفة } \\
\hline النسبة المئوية & العدد & الفئات & النسبة المئوية & العدد & الفئات \\
\hline 9,6 & 21 & $(37-26)$ & 3,7 & 8 & مفتش \\
\hline 29,4 & 64 & $(48-37)$ & 23,8 & 52 & أخصائي \\
\hline 61 & 133 & $(59-48)$ & 41,3 & 90 & مرشد \\
\hline \multirow[t]{2}{*}{100} & 218 & المجموع & 31,2 & 68 & أخصائي تتمية ريفية \\
\hline & & & 100 & 218 & المجموع \\
\hline \multicolumn{3}{|c|}{ عدد سنوات الخبرة } & \multicolumn{3}{|c|}{ المؤهل } \\
\hline النسبة المئوية & العدد & الفئات & النسبة المئوية & العدد & الفئات \\
\hline 52,8 & 115 & $(12-1)$ & 53,2 & 116 & دبلوم \\
\hline 39,4 & 86 & $(23-12)$ & 41,3 & 90 & بكالوريوس \\
\hline 7,8 & 17 & $(35-23)$ & 5,5 & 12 & دراسات عليا \\
\hline \multirow[t]{7}{*}{100} & 218 & المجموع & 100 & 218 & المجموع \\
\hline & & & \multicolumn{3}{|c|}{ التخصص } \\
\hline & & & النسبة المئوية & العدد & الفئات \\
\hline & & & 23,4 & 51 & إرشـاد زراعي \\
\hline & & & 28,4 & 62 & شعبة عامة \\
\hline & & & 48,2 & 105 & أخرى \\
\hline & & & 100 & 218 & المجموع \\
\hline
\end{tabular}

لإدارة المعرفة متوفر إلى حد مـا، و 2,8\% يرون أنها

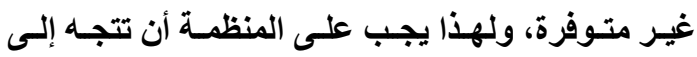

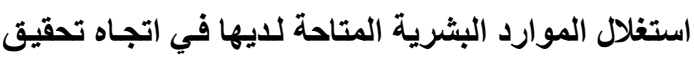

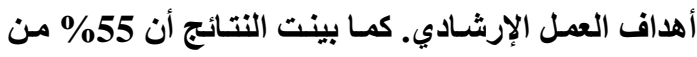

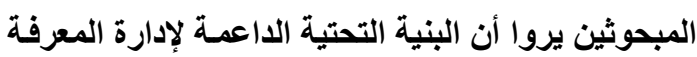

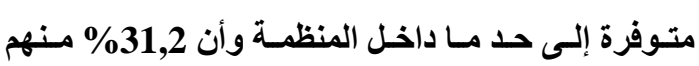

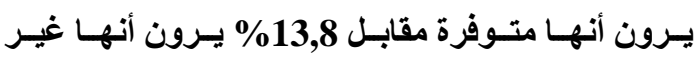

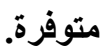

ثانياً : متطلبات إدارة المعرفة أوضحت النتائج في الجدول رقم (2) أن 77,5\% من المبحوثين يرون إن الثقافة التظيمية بين العاملين في الجهاز الإرشـادي متـوفرة، و20,6\% يـرون أن الثقافـة التنظيميـة متوفرة إلى حد مـا و1,8\% يرون أنها غير

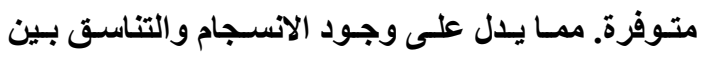
مختلف عناصر المنظمة لتحقيق الأهداف المطلوبة منها، و التكيف مـع التغيرات المتلاحقة وتوجه جهود المنظمـة

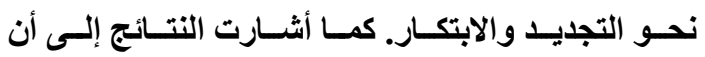
\%56,9 من المبحوثين برون أن العنصر البشري داخل المنظمة متوفر و40,4\% يرى أن العنصر البشري اللاعم جدول رقم ( 2 ): يوضح تو افر عناصر متطلبات إدارة المعرفة داخل جهاز الإرشاد.

\begin{tabular}{|c|c|c|c|c|c|}
\hline \multicolumn{3}{|c|}{ تكنولوجيا المعلومـات } & \multicolumn{3}{|c|}{ الثّقافة التنظيمية } \\
\hline النسبة المئوية & العدد & التوافر & النسبة المئوية & العدد & التوافر \\
\hline 25,2 & 55 & 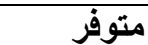 & 77,5 & 169 & متوفر \\
\hline 52,3 & 114 & إلى حل ما & 20,6 & 45 & إلى حـ ما \\
\hline 22,5 & 49 & غير متوفر & 1,8 & 4 & غير متوفر \\
\hline 100 & 218 & المجموع & 100 & 218 & المجموع \\
\hline \multicolumn{3}{|c|}{ إستراتيجية إدارة المعرفة } & \multicolumn{3}{|c|}{ العنصر البشرى } \\
\hline
\end{tabular}


Dorria M. Khairy, et al.,

\begin{tabular}{|c|c|c|c|c|c|}
\hline النسبة المئوية & العدد & التوافر & النسبة المئوية & العدد & التوافر \\
\hline 50,9 & 111 & متوفر & 56,9 & 124 & متوفر \\
\hline 40,8 & 89 & إلى حد ما & 40,4 & 88 & إلى حد ما \\
\hline 8,3 & 18 & غير متوفر & 2,8 & 6 & غير متوفر \\
\hline \multirow[t]{7}{*}{100} & 218 & المجموع & 100 & 218 & المجموع \\
\hline & & & \multicolumn{3}{|c|}{ توافر البنية التحتية } \\
\hline & & & النسبة المئوية & العدد & التوافر \\
\hline & & & 31,2 & 68 & متوفز \\
\hline & & & 55 & 120 & إلى حد ما \\
\hline & & & 13,8 & 30 & غير متوفر \\
\hline & & & 100 & 218 & المجموع \\
\hline
\end{tabular}

وتمهـل إلـى إمكانيـة تطبيـق إدارة المعرفـة داخل جهـاز الإرشـاد الزراعي وتنفيذ عملياته ولذلك ينبغي صياتتها وتدريب العاملين عليها أولاً. ثالثاً: تطبيق عمليـات إدارة المعرفـة في النظـام الإرشادي

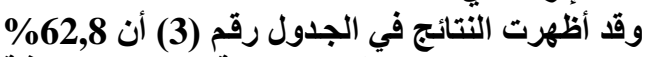

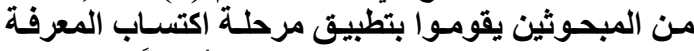

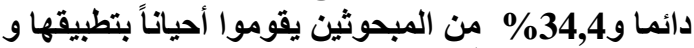

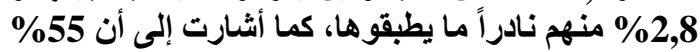

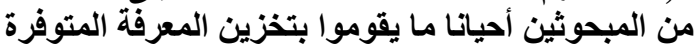

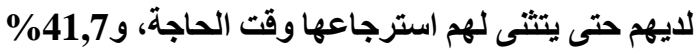

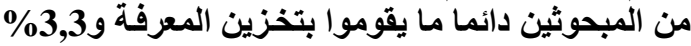
لا يقوموا بتخزين المعرفة المتوفرة لليهم.

كما أوضحت النتائج أن52,3\% من المبحوثين يرون أن تكنولوجيـا المعلومـات والاتصـال متوفرة إلى حد مـا، 2\%,25 منهم يرون أنها متوفرة بينمـ22,5\% من

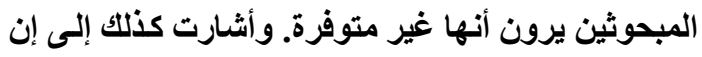
\% \%0,9 مسن المبحـوثين يـرون إن هنــاك إســتراتيجية



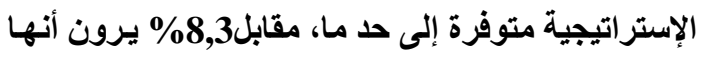

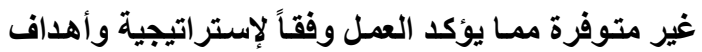
واضحة لبلوغ المطلوب منها. ومن النتائج السابقة يتضح أن متطلبـات إدارة المعرفـة متـوفرة في جهـاز الإرشــاد،

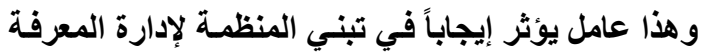
جدول رقم ( 3 ): يوضح تطبيق عمليات إدارة المعرفة داخل جهاز الإرشادئ

\begin{tabular}{|c|c|c|c|c|c|}
\hline \multicolumn{3}{|c|}{ تخزين المعرفة } & \multicolumn{3}{|c|}{ اكتساب المعرفة } \\
\hline النسبة المئوية & العدد & درجة التطبيق & النسبة المئوية & العدد & درجة التطبيق \\
\hline 41,7 & 91 & دائماً & 62,8 & 137 & دائماً \\
\hline 55 & 120 & أحياناً & 34,4 & 75 & أحياناً \\
\hline 3,3 & 7 & نادراً & 2,8 & 6 & نادراً \\
\hline o & 0 & $\gamma$ & 0 & 0 & $\gamma$ \\
\hline 100 & 218 & المجموع & 100 & 218 & المجموع \\
\hline \multicolumn{3}{|c|}{ تطبيق المعرفة } & \multicolumn{3}{|c|}{ نقل المعرفة } \\
\hline النسبة المئوية & العدد & درجة التطبيق & النسبة المئوية & العدد & درجة التطبيق \\
\hline 39,9 & 87 & دائماً & 63,3 & 138 & دائماً \\
\hline 55 & 120 & أحياناً & 34,4 & 75 & أحياناً \\
\hline 4,6 & 10 & نادراً & 1,8 & 4 & نادراً \\
\hline 0,5 & 1 & 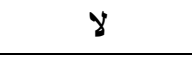 & 0,5 & 1 & $y$ \\
\hline 100 & 218 & المجموع & 100 & 218 & المجموع \\
\hline
\end{tabular}


ويضمن استمرارية المعرفة وتجددها والاستغلال الأمثل

للمعارف المتوفرة، وتضمن للمنظمة ريادتها باستخذامها

كمصادر لمز ايا تنافسية مستديمة.

رابعاً: أهم المشاكل التي تواجه تطبيق إدارة المعرفة

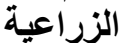

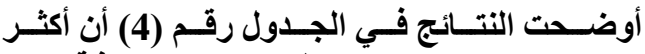

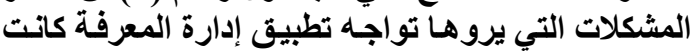

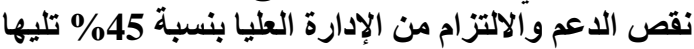

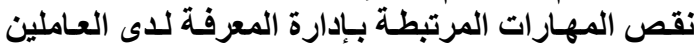

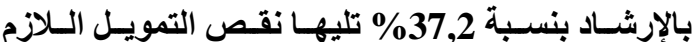

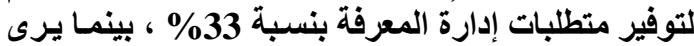
\% \%0,8 من المبحوثين أن الافتقار إلى التدريب المرتبط


كما يرى 36,2\% أن المنظمـة لا تثجع مشـاركة وتبادل

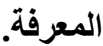

كما أوضحت أن 63,3\% من المبحوثين دائماً ما يقومون بنقل ومشاركة المعرفة مع الآخرين، و34,4\% منهم أحياناً ما يقومون بنقل ومشاركة المعرفة مع الآخرين و1,8\% نادراً ما يقومون بذلك مقابل 0,5\% لا

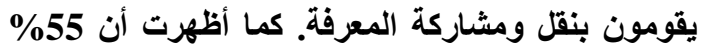
من المبحوثين أحياناً ما يطبقون المعرفة التي لديهم في عملهم داخل جهاز الإرشاد و39,9\% منهم دائما ما يطبقون معارفهم و4,6\% نادرا ما يقومون بتطبيق المعرفة مقابل 0,5\% لا يقومون بتطبيق المعرفة. وهذا يتفق مع توافر متطلبات إدارة المعرفة داخل جهاز الإرشاد وبالتالي يتمكن أعضاء الجهاز الارشادى لواتر الزراعى بمحافظة المنوفية من توليد معارف جديدة جدول رقم ( 4 ): يوضح التوزيع النسبي للمبحوثين وفقا لرأيهم في مشكلات تطبيق إدارة المعرفة.

\begin{tabular}{|c|c|c|c|c|c|c|}
\hline \multicolumn{2}{|c|}{ غير موافق } & \multicolumn{2}{|c|}{ إلى حـ ما } & \multicolumn{2}{|c|}{ 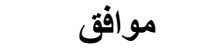 } & \multirow[t]{2}{*}{ المشكلات } \\
\hline 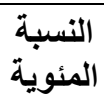 & 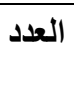 & 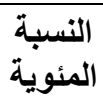 & 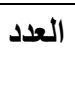 & المئوية - المبة & 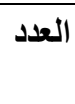 & \\
\hline 20,6 & 48 & 57,3 & 125 & 22 & 45 & العاملين ليس لايهم الوقت الكافي لإدارة المعرفة. \\
\hline 36,2 & 79 & 41,3 & 90 & 22,5 & 49 & المنظمة لا تثجع مشاركة وتبادل المعرفة. \\
\hline 31,2 & 68 & 47,2 & 103 & 21,6 & 47 & نقص الو الوعْي والفهم للفوائد المتحققة من تطبيق \\
\hline 28,4 & 62 & 45 & 98 & 26,6 & 58 & 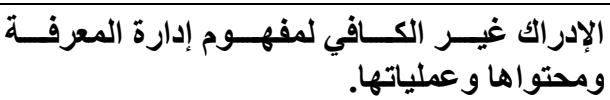 \\
\hline 16,5 & 36 & 38,5 & 64 & 45 & 98 & نقص الدعم والالتزام من قبل الإدارة العليا. \\
\hline 40,8 & 88 & 35,8 & 78 & 23,8 & 52 & الافتقار إلى التدريب المرتبط بإدارة المعرفة \\
\hline 15,1 & 33 & 47,7 & 104 & 37,2 & 81 & 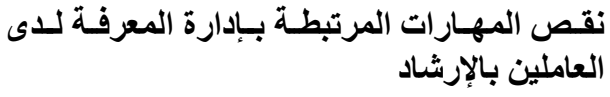 \\
\hline 27,6 & 60 & 39,4 & 86 & 33 & 72 & 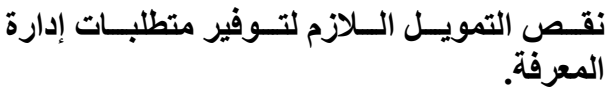 \\
\hline 11,5 & 25 & 28,4 & 62 & 60,1 & 131 & المعرفة الحــواجز و المكافـآت للمشـــــة فـي إدارة \\
\hline
\end{tabular}

المصدر: جمعت وحسبت من بيانات الاراسة

الإرشسادي يجب زيـادة عدد الندوات والبرامج التدريبية للمرشدين وتنوع موضوعاتها بنسبة 97,7\% و التحفيز

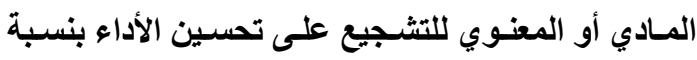

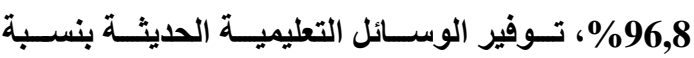

خامساً: مقترحات تطبيق إدارة المعرفة لتحسين الخدمة الإرشادية المقدمة للمزئ المارعين

اقترح المبحوثين كما أوضحت النتائج في الجدول رقم

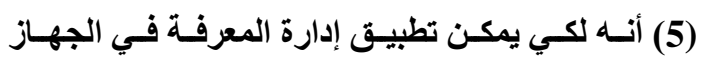


بنسبة 69\% وتوفير الوعي بأهمية تطبيق إدارة المعرفة داخل جهاز الإششاد بنسبة 57,8\% و توافر البنية التحتية اللازمة لإدارة المعرفة الزراعية 49,5\%.

96,3 وكذلك أشار 91,7\% إلى انه يجب توفير قاعدة بيانات تضم المعلومات الأساسية التي يحتاجها المرشدين

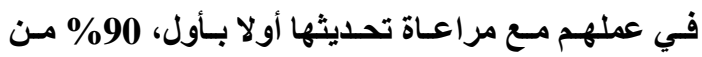
المبحوثين يرون الحاجـة إلى تعيين مرشـين زراعيين جدد من حديثي التخرج خريجي قسم الإرشـاد الزراعي، وجود شبكة تواصل بين العاملين في الجهاز الإرشادي جدول رقم (5): يوضح توزيع المبحوثين وفقا لمقترحات تطبيق إدارة المعرفة لتحسين الخدمة الإرشادية المقدمة

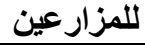

\begin{tabular}{|c|c|c|}
\hline 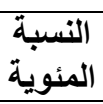 & 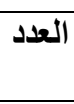 & المقترحات \\
\hline 69 & 150 & وجود شبكة تواصل بين العاملين في الجهاز الإرشادي \\
\hline 90 & 196 & الحاجة إلى تعيين مرشدين زراعيين جدد من حديثي التخرج خريجي قسم الإرشاد الزراعي \\
\hline 91,7 & 200 & تحديثها أولا بأبيال تات تضم المعلومـات الأساسية التي يحتاجها المرشدين في عملهم مـع مراعاة \\
\hline 96,3 & 210 & توفير الوسائل التعليمية الحديثة \\
\hline $\mathbf{9 7 , 7}$ & 213 & زيادة عدد الندوات والبرامج التدريبية للمرشدين وتتوع موضوعاتها \\
\hline 96,8 & 211 & التحفيز المادي أو المعنوي للتشجيع على تحسين الأداء \\
\hline 57,8 & 126 & توفير الوعي بأهمية تطبيق إدارة المعرفة داخل جهاز الإرشاد \\
\hline 49,5 & 108 & توافز البنية التحتية اللازمة لإدارة المعرفة الزراعية \\
\hline
\end{tabular}

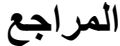

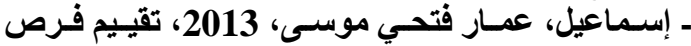

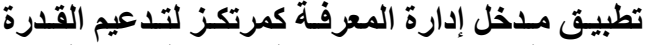

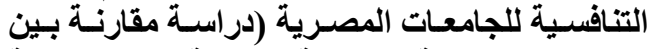

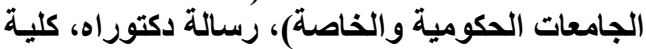

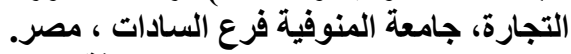

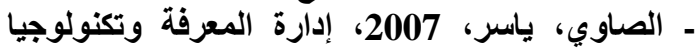
المعلومات، دار السحاب للنشر والتوزيع ،القاهرة، ـ الصباغ، عماد،2005، إدارة المعرفة ودورها في إرساء مجتمع المطلومات ، مصر.

http://www.hrdiscussion.com/hr855.html

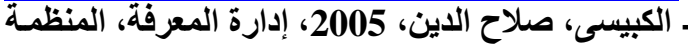

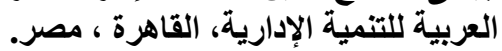
- بوعيشة، مبارك و ليليا بن منصور2012 " الإدة الدارة

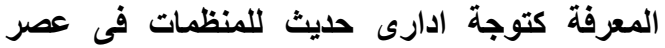

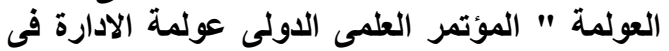
عصر العولمة (17-15 ديسمبر 2012) جامعة لبنان - حسن، عبد الباسط محمة، أصول البحث الاجتماعي، 1998، مكتبة وهبة، مصر.
1- دعم وتوفير متطلبات الثقافة التنظيمية عن طريق تئق تنمية ثقافة تنظيمية تعترف بإدارة المعرفة والإبداع والتحفيز عليها من خلال: تئن

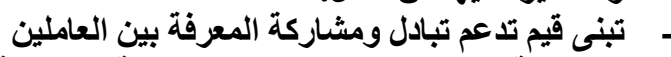
من ناحية وبين الاقسام والإدارات المختلفة من ناحية اخرى. - العمل على تعزيز الثقة المتبادلة بين العاملين لتبادل المعرفة والخبرات.

2- دعم وتوفير المتطبات الادارية ،حيث ان إنبرات إدارة المعرفة تتطلب نمطاً غير تقليدى من القيات القيادة تركز على أهمية التواصل مع الأخرين. 3- توفير البنية التحتية الداعمة لإدارة المعرفة فى جهاز الارشاد الزراعى .

4- منح العاملين الحرية فى إستخدام وتطبيق المعارف

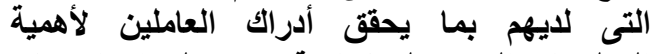
المعلومات التى يمتلكونها وقدرتهم على ايجاد معنى لإنى لإنى

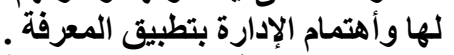

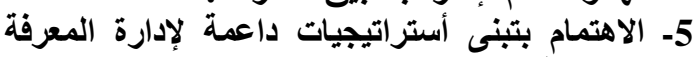




- عبيد،عصام،2016،تطبيق ادارة المعرفة فئي المؤسسات، على الموقع:

http://www.hrdiscussion.com/hr4521.html

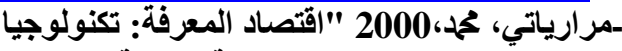
المعلومات والتعريب"، المئي المجلة العربية (النادي

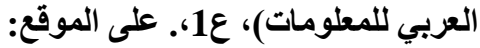

http://arabcin.net/arabiaall/2000/2.html

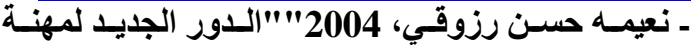

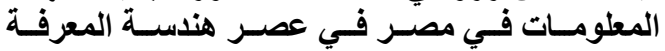

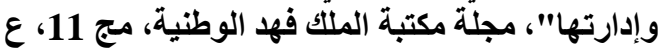
2، مارس 2004.

- Kucza, Timo, " Knowledge Management Process Model ", Technical Research Centre of Finland, VTT Publication, http://www.vtt.fi/inf/pdf/publications,2001
- حمادي،عبلة، 2013"دور إدارة المعرفة في بناء

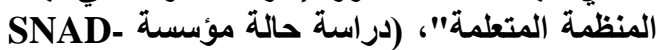

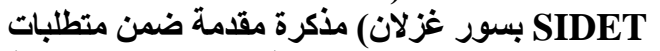

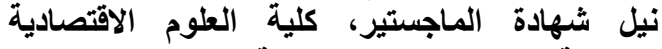

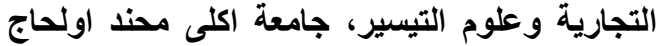
البويرة ،الجزائر.

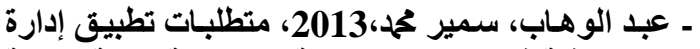

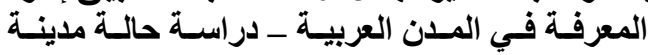

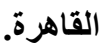

http://www.blastak.blogspot.tcom/2013/5b log-post-901.html 
Dorria M. Khairy, et al.,

\title{
REALITY APPLICATION AGRICULTURAL KNOWLEDGE MANAGEMENT IN AGRICULTURAL EXTENSION SYSTEM IN MENOUFIA GOVERNORATE
}

\author{
Dorria M. Khairy, E. S. A. Shahien and Samar G. M. Shair \\ Agricultural Extension and Rural Sociology, Faculty of Agriculture, Menoufia University
}

\begin{abstract}
The study aims at identifying the reality of the application of knowledge management in the agricultural extension system by examining the availability of knowledge management requirements and identifying the extent of the application of agricultural knowledge management processes within the agricultural extension system, a sample of 218 was collected. The results indicated that the organizational culture as a knowledge management requirement was $77,5 \%$ while knowledge management processes were average. The most common problems facing knowledge management application were the lack of support and commitment from senior management by $45 \%$ and lack of knowledge management skills among extension workers the participants suggested that the number of seminars and training programs for instructors and the diversity of their subjects should be increased by providing modern educational means.
\end{abstract}

Key words: Knowledge, Knowledge Management, Agricultural Knowledge Management 